\title{
Research on Landscape Design of Building Information Model in Ecological Restoration Projects of Cities along the Yangtze River
}

\author{
Jinhong XIAN, Yaou ZHANG*
}

\begin{abstract}
The urban landscape pattern, process and function have three-dimensional characteristics, and the three-dimensional analysis of urban landscape elements is one of the important trends in the development of urban landscape research. However, the current research on the visualization of urban landscape in three dimensions and the application of related models still needs to strengthen. Based on the research of the ecological restoration process, this paper combines the current situation of urban landscape construction along the Yangtze River in China and deduces the development trend of urban landscape planning. Based on Building information model (BIM), this article combines Revit software to design landscape construction drawings, and summarizes the specific design process and the current unsolvable problems. As an experimental building information model (BIM) software construction drawing design attempt, this article explores the urban ecological water conservancy landscape planning and design path, and demonstrates it in combination with specific cases. Therefore, this paper conducts modeling based on three-dimensional virtual landscape, which conducts virtual landscape design and provides technical ideas for the development of this technology.
\end{abstract}

Keywords: Building Information Model (BIM); cities along the Yangtze River; ecological restoration project; landscape design

\section{INTRODUCTION}

After the $18^{\text {th }}$ National Congress of the Communist Party of China listed the construction of ecological civilization as a national key strategic goal plan, the civilization construction method for ecological environmental protection has put forward higher requirements for the planning and construction of cities along the Yangtze River Basin. In this process, among the 32 pilot cities for the construction of ecological civilization in the Yangtze River Basin, under the premise of adapting to the development needs, the cities along the Yangtze River Basin have applied a variety of advanced technologies to carry out standardized construction to make them in the ecological civilization [1, 2]. The Yangtze River Basin is located in the waist and belly zone of the entire Chinese territory. It covers 10 provinces and cities including Sichuan, Hunan, Hubei, Jiangxi, Anhui, Jiangsu, and Shanghai, with a basin area of 1.8 million square kilometers and a total population of close to 400 million. Its area and population are about 9 times and 4 times that of Japan's Pacific Economic Belt, respectively, and 3.5 times and 5 times that of the European Union's Rhine-Ruhr-Seine Economic Belt [3]. Although the total economic volume is not on par with the large economic belts in the world, the annual GDP growth of more than $10 \%$ has made the Yangtze River Basin a regional economic belt with the fastest economic growth and huge growth potential in the world. Yangtze River Basin has successively developed the economic continuous belt of the upper urban agglomeration centered on Chongqing, the economic continuous belt of the midstream urban agglomeration centered on Wuhan, the economic continuous belt of the lower urban agglomeration centered on Nanjing, and Shanghai as the center, which is the economic continuous belt of the Yangtze River Delta urban agglomeration. At present, these four major urban agglomeration economic belts have become one of the regions with the most dense industrial production and service industries in the country.

The construction of the Yangtze River Economic Belt is naturally inseparable from the Yangtze River, especially for the economic development and construction of cities along the Yangtze River [4]. Cities along the Yangtze River Basin are not only ecologically sensitive areas in the Yangtze River Basin, but also the second line of ecological defense of the Yangtze River. To promote the development and construction of the Yangtze River Economic Belt, it is necessary not only to fully consider the long-term interests of the country and the nation, but also to persist. With the continuous deepening of the market economy, the links among cities in the Yangtze River Basin have gradually evolved from links under administrative intervention to market-oriented links. The content, breadth, and depth of inter-city links have undergone profound changes. Many scholars have also begun to get involved in various forms of "flow" links between central cities and their urban agglomeration economic belts. The "flow" of urban spatial interaction roughly includes five basic forms: people flow, logistics, capital flow, information flow and technology flow. In the study of urban spatial interaction, some scholars use the heat conduction method of physics to divide the basic forms of spatial interaction such as the flow of people, logistics, capital, information, and technology among cities and among cities and regions. There are three types of convection, conduction, and radiation [5]. In recent years, the ecological restoration planning and construction of cities along the Yangtze River Basin has achieved initial results, forming a large pattern integrating railway, waterway, aviation and other transportation systems, and is working hard to build a trillion economic corridor along the river. When the country conducts strategic planning and layout, it must fully consider the city's own development, which shows that the country attaches great importance to cities along the Yangtze River. Moreover, under the Yangtze River ecological protection mechanism, cities along the Yangtze River Basin not only form an alliance with ecology, but also walk with environmental protection, actively respond to the call of the state, and raise funds locally for ecological and environmental protection.

In view of the increasingly prominent and intensified urban development contradictions, the scarcity of land resources and the destruction of the urban environment 
have become the main constraints of current urban development. The ecological optimization of urban landscapes emphasizes the agglomeration, maintenance, and organic connection of urban functions. For urban landscape ecology, due to the increasingly significant impact of the elements constituting the urban landscape on the three-dimensional level, the base plane of many urban landscape elements has undergone vertical displacement, making the agglomeration function of the city in the vertical direction more directly affect the city. The twodimensional feature analysis of traditional urban landscape patterns can no longer meet the needs of current urban landscape research. At the same time, due to the threedimensionalization of urban elements, their interaction with the surrounding ecological environment has become more complex, making the analysis of three-dimensional urban characteristics the key to exploring the ideal urban landscape pattern. In order to investigate the landscape design of the building information model in the ecological restoration projects of the urban agglomerations in the Yangtze River basin, this paper has carried out the research on the ecological protection of the Yangtze River, which has important practical value and significance. From the perspective of long-term development planning, the Planning and construction are not only an important foundation for promoting economic development, but also an important way to accelerate economic development. For this reason, under the concept of sustainable development, on the one hand, great attention should be paid to the ecological environment protection of the Yangtze River Basin, and on the other hand, ecological and economic benefits should be effectively integrated, thereby bringing more safety, reliability, and unlimited potential to urban development sustainable development prospects.

\section{RELATED THEORETICAL RESEARCH}

\subsection{Analysis Framework for the Ecological Restoration}

Ecological restoration in a narrow sense refers to the restoration and restoration of damaged land, water bodies, soil, habitats, etc. by engineering, chemical, biological, and greening methods to achieve pollution elimination, ecological function and landscape restoration, resource reuse, etc. Ecological restoration in a broad sense includes all human activities and surface processes aimed at improving the quality of the ecological environment $[6,7]$. As the ecosystem is a complex giant system, ecological restoration in a narrow sense often "treats the symptoms but not the root cause", so the implementation of systemic ecological restoration for specific areas has gradually become a consensus. This paper draws on relevant theories such as man-land system science, landscape ecology, ecology, etc., and tries to analyze the connotation of ecological restoration in a broad sense (Fig. 1).

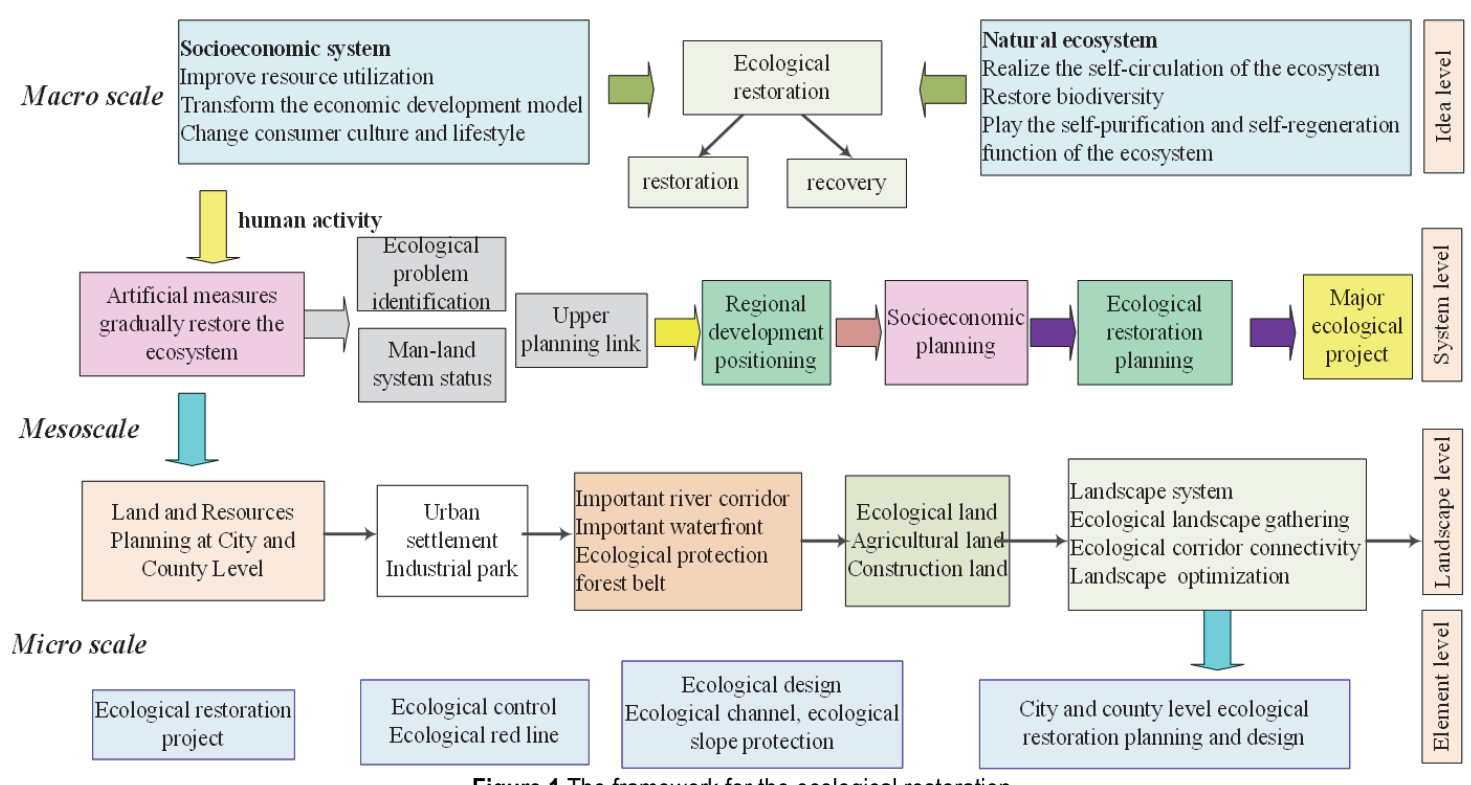

Figure 1 The framework for the ecological restoration

According to the theory of man-land relationship, ecological restoration can be divided into socio-economic systems and natural ecosystems. For damaged ecosystems, artificial measures are used to carry out ecological reconstruction and ecological repair, and ecologically fragile areas and ecologically sensitive areas shall be delineated for ecological management and control. The district promotes ecological restoration. Due to the high level of artificialization of the current natural ecosystem, the process of ecological restoration in practice requires a combination of "repair" and "recovery". Macro-scale ecological restoration is not only the spatial layout of various ecological projects, ecological control, and ecological measures, but also the guidance of regional social and economic development under the constraints of ecological restoration goals [8]. Adjusting the direction of social and economic development in accordance with the concept of ecological restoration, coordinating economic activities and ecological restoration activities through the establishment of mechanisms such as ecological compensation, and formulating ecological restoration plans at the regional level are the ways to achieve macroscale ecological restoration. The objects of meso-scale ecological restoration are mainly various landscape ecological elements. The macro-scale ecological restoration plan has implemented by the adjustment of the landscape structure, the optimization of the landscape pattern, and the improvement of the ecological functions of 
the landscape with the county-level territorial space planning. The micro-scale ecological restoration is similar to the traditional narrow ecological restoration concept, and is a specific way to implement ecological restoration at the operational level. Through the county-level ecological restoration special planning, the layout of ecological restoration projects, the formulation of landscale ecological control rules, and the implementation of ecological design standards suitable for regional conditions.

\subsection{BIM in Landscape Design}

BIM technology first originated in the United States, and its original intention was not only used in the construction industry. The B in "BIM" refers to Building, and Building cannot completely refer to construction. It also refers to the construction engineering industry. BIM technology has extended to municipalities and roads [9]. The landscape industry has certain similarities with the construction industry, and the landscape industry needs BIM technology concepts.

(1) In terms of design thinking and operation process, both construction engineering and landscape engineering projects need to go through the stages of pre-analysis, concept generation, scheme design, design drawing, construction practice, operation, maintenance management, etc. Therefore, relevant technical methods can be used for reference. At the same time, in terms of construction materials, the material properties used by the two have similarities.

(2) The two-dimensional CAD design process of landscape projects is based on the civil engineering major (Fig. 2), and the greening, hydropower and structure majors are supplemented by the model. If the civil engineering major's base drawings are adjusted, other majors will copy the base maps After that, the corresponding changes need to be made one by one; therefore, there are problems such as troublesome drawing modification, low work efficiency, and poor collaborative design among various disciplines [10]. However, these problems can be effectively solved by BIM technology.

(3) The BIM technical concept emphasizes that the result delivered to Party $\mathrm{A}$ is not just a two-dimensional drawing, but also the BIM integrated model is the result. The comprehensive model includes pipeline model, material model, three-dimensional model, etc., with complete project attribute information. When the project is completed, the BIM comprehensive model is delivered. Once the building needs maintenance, the owner opens the three-dimensional model and can clearly see the project pipeline of comprehensive model information such as materials, equipment, materials, etc., which can understand problems in time and propose solutions. While traditional professionally archived drawings cannot achieve similar results [11].

Therefore, some technologies and concepts in the construction industry can be borrowed from the landscape industry, and methods can be modified according to the development of the landscape industry to meet the needs of professional development [12]. The thesis takes landscape construction drawing design as the research object, based on the whole life cycle design stage. With the BIM technology concept as the guiding ideology, this paper discusses the specific steps and processes of the Revit software in the BIM technology in the landscape construction drawing design, and proposes the design. Difficulties in the process and problems that cannot be solved currently are for reference in other studies.

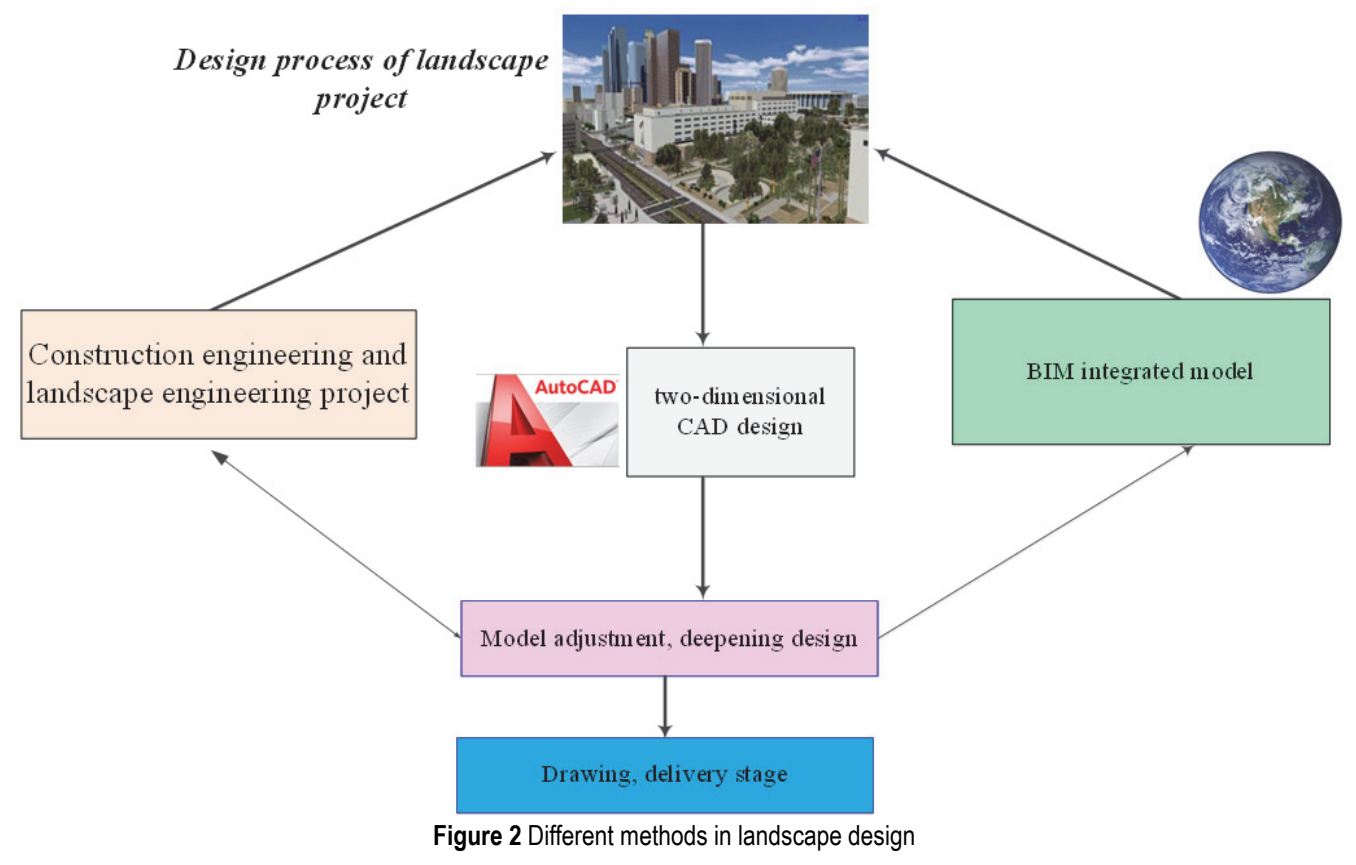

3 LANDSCAPE DESIGN OF CITIES ALONG THE YANGTZE RIVER BASED ON BIM

3.1 Describe the Landscape Structure

The three-dimensional landscape modeling is based on the overall characteristics of the landscape and carries out a distributed morphological description [13]. This paper uses the camera for discrete data collection, the camera shoots continuous video, after data processing, the actual panoramic image is generated, and AutoCAD or $3 \mathrm{ds}$ MAX 
is used to process the landscape environment image to organize the panoramic image to generate a virtual space. In the virtual space, the operator performs operations such as looking up, looking down, near view, and far view, and begins to set the geometric data of the real scene, describe the landscape shape, and make the described landscape shape meet the multiple spaces shown in Fig. 3.

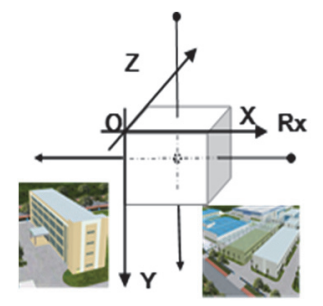

Figure 3 Dynamic description of $3 \mathrm{D}$ virtual landscape
In this paper, the establishment of a virtual landscape model requires the use of the above description space to establish a single model component. The changing factors are implanted into the description space according to the changing characteristics, and the virtual landscape geometric modeling is established.

\subsection{Analysis of Landscape Properties}

Based on the use of dynamic description space to describe the landscape structure, the external and internal attributes of the landscape are analyzed. In the analysis process, the mapping relationship of landscape appearance attributes is shown in Fig. 4.

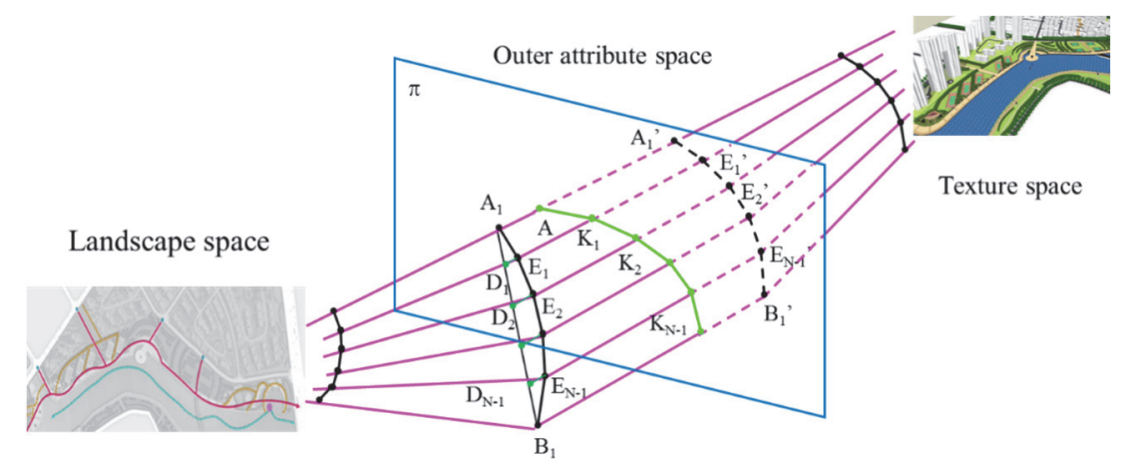

Figure 4 Characteristic relationship of landscape appearance attributes

\subsection{Virtual Landscape Design based on Building Information Model}

In the study of urban landscape ecology, it is pointed out that the characteristics of urban landscape pattern are closely related to urban functions. The urban landscape not only determines its own structure and pattern characteristics with its strong radiation and penetration ability, but also has a significant improvement and restraint effect on the structure of other surrounding landscape types [8]. The functional connection of traditional cities relies on a two-dimensional transportation network. The material and energy circulation in the urban landscape, and the information exchange capacity all depend on the spatial density and interconnection of the transportation network. At the same time, large-scale transportation and urban construction also lead to the isolation of natural habitats [14]. The three-dimensional network of urban functional connection refers to the network connection between urban functional elements, manifested as the channels of logistics, energy flow and information flow interspersed, overlapped or even intertwined, forming a three-dimensional urban functional network. Among them, the network node is the city function center, and the network corridor is the landscape function flow formed based on the landscape elements, and together constitutes the connection link between the city and the region.

In the research of three-dimensional urban landscape, it is necessary to extract the ground and surface elevation information of urban landscape to obtain the threedimensional characteristics of urban landscape. The basic idea of extraction is mainly based on the multi-reflection characteristics of the laser reflection signal, which can simultaneously measure points on the ground, treetops, or building tops. By measuring the height difference between the first echo and the last echo of the same group of laser waves, the height of the urban landscape can be determined. The specific process mainly includes distinguishing ground points from ground surface points and generating a regularized surface elevation model. The implementation of the project is mainly divided into data preprocessing, urban planning virtual landscape model construction and integration, system function development and application.

Based on the TerraExplorer pro components of the Skyline series, a virtual planning simulation system for Guangzhou Auto City based on real 3D images was developed on the net platform. Specific realization function includes 3D simulation interactive browsing and roaming. Three-dimensional simulation interactive browsing and roaming of the planned target is the form of three-dimensional real-time simulation. It guides users into a realistic and visualized interactive environment, which is vivid, intuitive and interactive. Information dynamic query and analysis evaluation provides planning information query, analysis and statistics functions in a threedimensional visualization environment. System users can carefully study the land, roads, traffic, and other relevant conditions in the area of interest.

After the overall three-dimensional modeling design of the virtual landscape is completed, the dynamic browsing of the three-dimensional modeling is performed to dynamically browse and display the virtual landscape to view the virtual effect of the three-dimensional modeling. Analyze the landscape modeling attributes in each area of 
the virtual landscape, set the light source and visual points, browse the dynamic image quality of the shape and internal structure of the three-dimensional virtual landscape, and perform color rendering according to the actual situation. To make dynamic 3D renderings, it is necessary to triangulate complex 3D entities and smooth 3D mesh data to ensure the fluency of dynamic browsing [15]. Therefore, the interface language is added based on the hardware settings. In order to reduce the number of repeated data recordings, the fan-shaped method is used to divide the virtual landscape performance node position, and the virtual dynamic demonstration track is set according to the attributes and the level of association between the models in the landscape to realize the dynamic browsing of the virtual landscape.

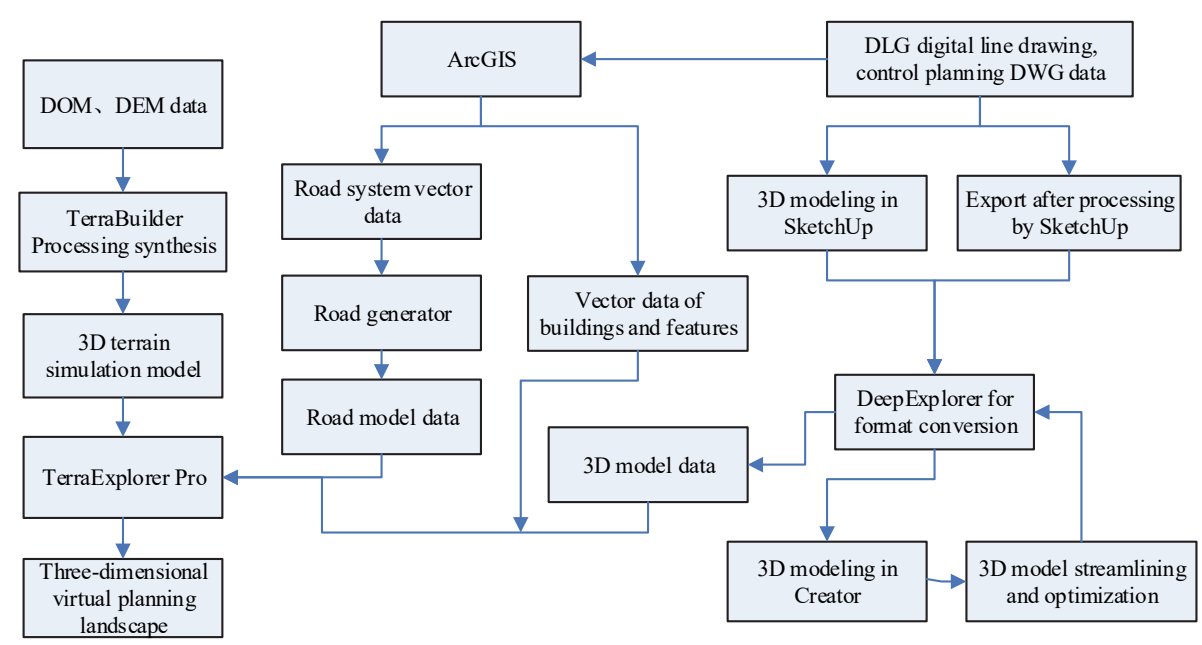

Figure 5 The construct of supply chain knowledge

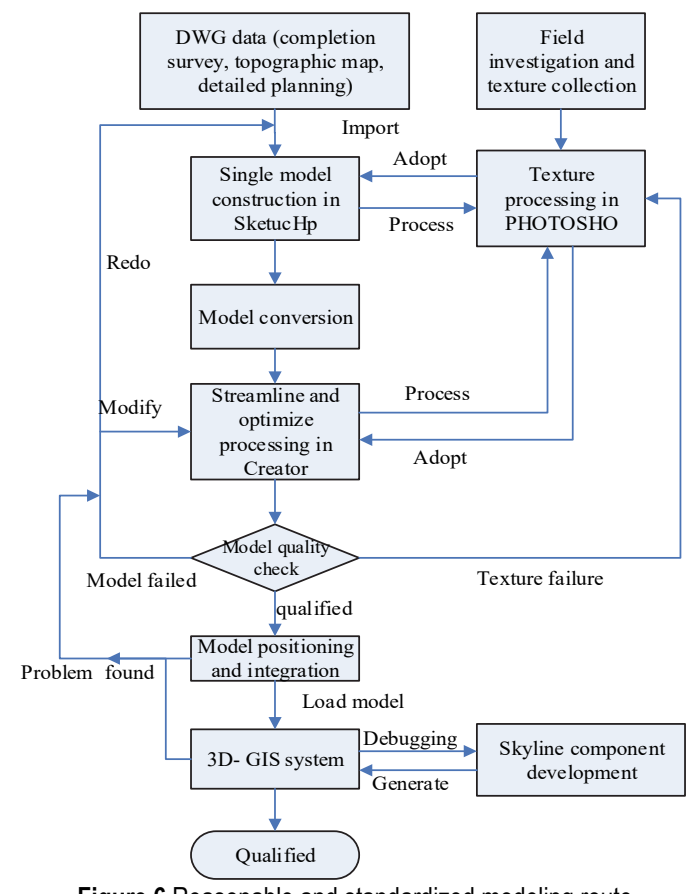

Figure 6 Reasonable and standardized modeling route

The virtual landscape model is stretched in the longrange and close-range, and while the dynamic stretch is being carried out, the scale and structure of the virtual scene will not be affected by the dynamic stretch. The dynamic image contour of the model is guaranteed only with the number of frames. The dynamic change occurs due to the change, thus realizing the virtual design of threedimensional landscape [15].

\subsection{D Model Library Construction}

The construction of the 3D model library is divided into general buildings, existing key buildings, planned buildings, and various features and facilities. General buildings include more than 20000 buildings, with simple attributes such as the number of stories, the height of the building, and the type of building. The key buildings have refined modeling of the existing buildings of 17 companies, totaling more than 100 buildings. There are more than 20000 ground features including grassland, fences, overpasses, streetlights, roads, green plants, road flowerbeds, pedestrian walkways, sky, and water areas. Planning buildings model the planning buildings of 10 units, totaling more than 40 buildings.

\section{SIMULATION EXPERIMENT AND RESULTS}

In order to verify the ability of the designed 3D virtual landscape to reflect the real landscape, select an actual landscape, use the Virtual RealityPlatform software, and use the method in the text and the traditional method to perform the virtual design of the $3 \mathrm{D}$ landscape.

\subsection{Experiment Preparation}

Build a simulation test platform for experiments. The hardware facilities include large-scale three-dimensional LCD screens, graphics workstations, computers, threedimensional glasses, scanners, digital cameras, video cameras, etc. Set the parameters in the experimental platform as shown in Tab. 1.

Table 1 Experimental platform parameters

\begin{tabular}{|l|c|}
\hline \multicolumn{1}{|c|}{ Name } & Parameter setting \\
\hline Server software & Windows server 2012 \\
\hline Server hardware & Memory 2 G, hard disk 128 G \\
\hline Server system & Ggda - 25T3 \\
\hline Database & DB2/SQL \\
\hline Client browser & IE 10.0 \\
\hline Client hardware & Memory 2 G, hard disk 128 G \\
\hline Test tool & Dev test \\
\hline
\end{tabular}


At the same time, the experimental parameters are set, and the results are shown in Tab. 2 .

Table 2 Experimental parameters

\begin{tabular}{|l|c|}
\hline \multicolumn{1}{|c|}{ Name } & Experimental Parameter \\
\hline Data information & $64-128 \mathrm{~GB}$ \\
\hline System memory & $128 \mathrm{~GB}$ \\
\hline Operating frequency & $300 \mathrm{MHz}$ \\
\hline CPU frequency & $360 \mathrm{MHz}$ \\
\hline
\end{tabular}

After the parameters are set, the data information statistics of the virtual design scene, including paper topographic maps, building structure maps, current land occupation maps, and other data are performed. This paper uses a scanner to scan the topographic drawings of the landscape, upload the obtained data to the experimental platform, establish a three-dimensional scene virtual landscape model, and import the scene model into the $3 \mathrm{ds}$ MAX software.

In order to better distinguish the three-dimensional virtual scenes under the two design methods, this paper divides 10 different scenes. The detailed data is shown in Tab. 3.

According to the landscape data in Tab. 3, the landscape three-dimensional virtual design is carried out, and the effect analysis is carried out according to the obtained design image.

Table 3 The landscape data
\begin{tabular}{|c|c|c|c|}
\hline NO. & Fixed point & Number of objects & Number of triangles \\
\hline A1 & 16548 & 248 & 7684 \\
\hline A2 & 18396 & 256 & 7864 \\
\hline A3 & 64 & 16 & 48 \\
\hline A4 & 56 & 12 & 46 \\
\hline A5 & 48 & 18 & 36 \\
\hline A6 & 42 & 12 & 28 \\
\hline A7 & 40 & 10 & 28 \\
\hline A8 & 36 & 9 & 24 \\
\hline A9 & 28 & 7 & 18 \\
\hline A10 & 20 & 5 & 9 \\
\hline
\end{tabular}

\subsection{Result Analysis}

Taking the virtual design renderings proposed in the article as the experimental group, and the virtual renderings under the traditional design as the control group, the landscape virtual design renderings shown in Fig. 7a is the Landscape layout, Fig. 7b, and Fig. 7c are obtained.

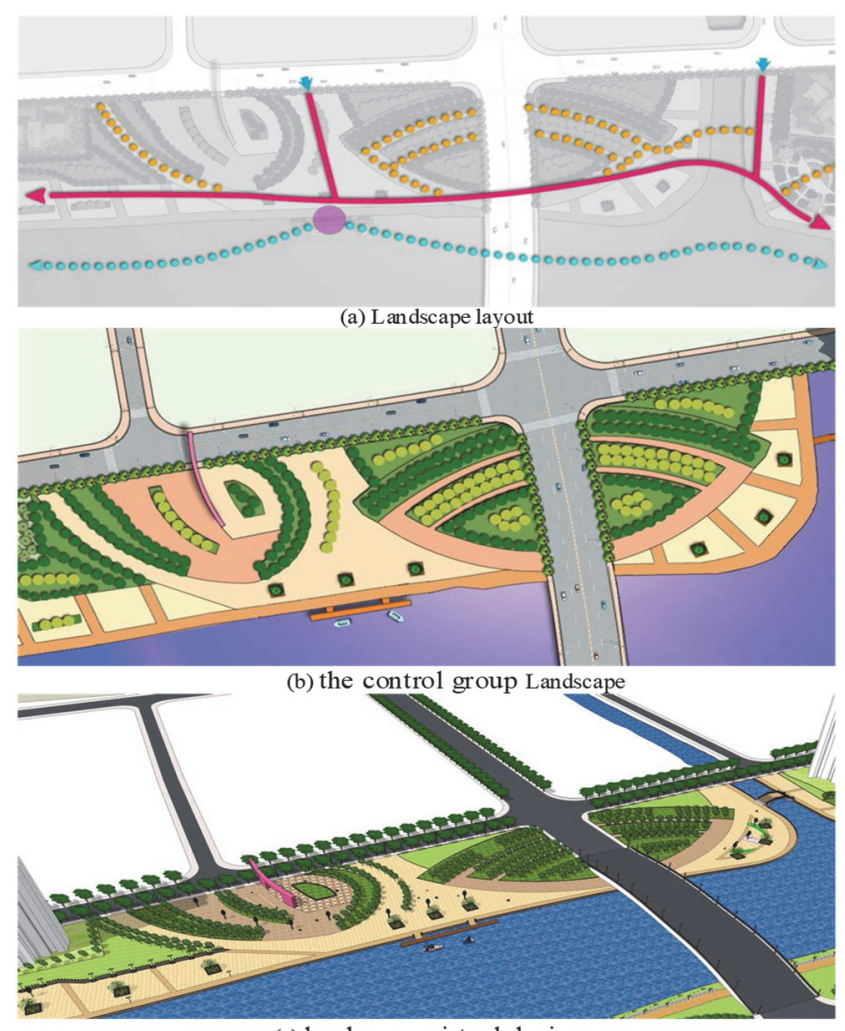

(c) landscape virtual design

Figure 7 Reasonable and standardized modeling route

By comparing Fig. 4 and Fig. 5, we can see that the virtual scene in the experimental group has clear internal structure, reasonable color rendering, high fidelity, and better visual effects. In the control group under the traditional design method, the internal structure is not clear, the color fusion is low, and there is no three-dimensional visual impact. For these two sets of virtual design renderings, statistics are made on 5 artistic effects among them, and the results are shown in Tab. 4.
Table 4 Experimental parameters

\begin{tabular}{|c|c|c|}
\hline NO. & Test group & Control group \\
\hline 1 & 96.5 & 90.1 \\
\hline 2 & 96.2 & 89.6 \\
\hline 3 & 96.7 & 89.6 \\
\hline 4 & 96.8 & 88.7 \\
\hline 5 & 95.8 & 89.4 \\
\hline
\end{tabular}

According to the calculated results in Tab. 4, the artistic effect on the experimental group is $95 \%$, and the average result is $95.86 \%$. The art effect of the control group under the traditional design is $90 \%$, with an average of 
$89.3 \%$, which is $6.56 \%$ lower than the art effect of the proposed virtual design.

\subsection{Discussion}

In the strategic plan for the development of ecological and environmental protection of the Yangtze River, this paper conducted in-depth understanding of the actual situation of ecological protection along the Yangtze River through various aspects and conducted on-site surveys to enable them to focus on the ecological protection and green development of the cities along the line. As the cities along the line are located in the largest area along the Yangtze River, this paper makes an effective scientific development plan. First, promote the transformation and upgrading of the chemical industry along the Yangtze River, re-plan the layout of the chemical industry, prepare plans for related industrial parks, change the decentralized development pattern, and encourage chemical companies to move into the parks and concentrate their layout. Second, promote the ecological restoration of lakes and wetlands, focusing on the development of water ecological protection and restoration projects in key urban river sections such as Shahe, Bailinhe, Juanqiaohe, etc., and do a good job in the planning and construction of urban wetland parks. The specific measures are as follows:

1) Strengthen the promotion of the concept of ecological civilization:

On the premise of adhering to the concept of respecting and protecting nature, the construction of an ecologically civilized city must not only fully mobilize the active participation of the whole society, but also form a longterm management mechanism. On the one hand, publicity should be increased so that in the effective publicity of the construction of an ecologically civilized city involving all citizens, it can not only carry out the precise positioning of public welfare, but also make the concept of ecological restoration and ecological protection of the Yangtze River rooted in the hearts of the people. In attracting the active participation of people from all occupations, fully mobilize and enhance their enthusiasm, so that they can not only reach a consensus on the construction of an ecologically civilized city, but also form a good public opinion atmosphere and environment. Under the premise of continuously improving the intensity and level of publicity, the eco-environmental awareness of saving resources can be internalized in the heart, externalized in action, and can be effectively practiced through practical actions. On the other hand, technical training and guidance should also be effectively strengthened. With the support of strong technical theory, not only can it effectively draw on and learn from the advanced water conservancy project of construction experience, but also, under the guidance of the innovative concept of sponge city, it can target the river Reasonable development and construction of engineering and riverside landscapes. Under the premise of ensuring ecological priority, not only natural restoration and natural protection must be carried out, but also water conservancy project must be comprehensively carried out, so that it can play the actual role of water conservancy projects. The function can also reflect the ecological landscape construction of the Yangtze River back to nature.

2) Coordinate and organize the construction of pilot projects:

In this process, the construction of cities along the Yangtze River, under the premise of actively promoting the construction of pilot projects, refining tasks and objectives, and effectively implementing the responsibility mechanism, not only must promote its efficient and orderly work, but also focus on pilot projects. The project has evaluated by authoritative institutions, so that during the pilot tracking process, it can not only effectively implement the assessment tasks to all departments and positions, but also form a complete supervision and accountability mechanism, so that its tasks and objectives can be effectively implemented and actively promote Open government information and accept public supervision. In addition, the demonstration role of the pilot should be strengthened. Under the premise of actively promoting the construction of the pilot project, through continuous summarization and refinement, advanced concepts and good policies should have given full play to the demonstration and leading role in the active promotion, which is practical and effective.

3) Solving the plight of urban ecological development:

In the planning and construction of ecologically civilized cities in the Yangtze River Basin, there have always been not only institutional flaws, but also the development dilemma of excessive costs and similar patterns, which caused them to encounter a bottleneck crisis in the construction of ecologically civilized cities. To this end, in the construction and development of an ecologically civilized city, based on the principles of respecting, conforming to and protecting nature, Yichang has broken through the ecological city construction dilemma by creating the construction goal of "surrounding mountains outside the city and connecting green spaces in the city". Making it not only proud of its unique urban charm along the Yangtze River, but also won the honorary title of the nation's top ten livable cities.

\section{CONCLUSIONS}

Through the preliminary research of this article, it is concluded that the concept of BIM building information model will run through the whole design process in the future. It is foreseeable that BIM technology will become more and more important in the engineering construction industry. Based on the future trend of the conversion of two-dimensional drawings to three-dimensional drawings, BIM research can also conduct more in-depth research on project management and later maintenance. The development process of engineering construction software has gone through hand-drawn drawings, electronic drawing boards, parameterization, and threedimensionalization finally entered the current BIM stage. Many years ago, under the slogan of "throw away the drawing board", we promoted the application of CAD software. Although it did not meet the initially expected "assisted design" functional requirements, only "assisted drawing" has also played a role in improving industrial efficiency. CAD software is an improvement on the technical level within the framework of the original industry operation process. BIM is a new generation of force to promote process and concept changes. It is booming in the construction industry, and the budding 
landscape industry has emerged.

The modeling and virtual design based on $3 \mathrm{D}$ virtual landscape proposed in this paper pay more attention to the matching level between landscape models, divide the virtual landscape image according to its characteristics and attributes, realize the virtual design of virtual landscape, and enhance the artistic effect of virtual imaging. The research results show that the designed landscape virtual imaging effect is bright in color, realistic in shape, clear in structure, and has higher application value. However, the current design is not perfect enough, and further optimization is needed in dynamic browsing.

\section{REFERENCES}

[1] Yang, S. (2019). Innovative research on landscape design of the Yangtze River mountainous basin. Landscape Architecture, 2(1), 14. https://doi.org/10.31058/j.la.2019.21002

[2] Kong-Jian, Y. U., Yi-Yong, C., Chun-Lian, W., \& Di-Hua, L. I. (2011). Ecological restoration of a reclaimed island landscape in the Yangtze River. Resources and Environment in the Yangtze Basin. https://doi.org/10.1080/00405000.2010.522047

[3] Li, F., Ye, Y., Song, B., \& Wang, R. (2015). Evaluation of urban suitable ecological land based on the minimum cumulative resistance model: a case study from Changzhou, China. Ecological Modelling, 318(1), 194-203. https://doi.org/10.1016/j.ecolmodel.2014.09.002

[4] Jiang, C. \& Zhang, L. (2016). Effect of ecological restoration and climate change on ecosystems: a case study in the threerivers headwater region, China. Environmental Monitoring \& Assessment, 188(6), 382. https://doi.org/10.1007/s10661-016-5368-2

[5] Yanglin, C., Bin, D., Lingna, C., Xiang Gao, \& Yuhuan ,C. (2019). Study on habitat suitability of overwintering cranes based on landscape pattern change-a case study of typical lake wetlands in the middle and lower reaches of the Yangtze River. Environmental Science and Pollution Research International, 26, 14962-14975. https://doi.org/10.1007/s11356-019-04697-y

[6] Fang, G., Yuan, T., Zhang, Y., Wen, X., \& Lin, R. (2019). Integrated study on soil erosion using rusle and gis in yangtze river basin of Jiangsu Province (China). Arabian Journal of Geosciences, 12(5). https://doi.org/10.1007/s12517-019-4331-2

[7] Kong, L., Zheng, H., Rao, E., Xiao, Y., Ouyang, Z., \& Li, C. (2018). Evaluating indirect and direct effects of ecorestoration policy on soil conservation service in Yangtze River basin. Science of The Total Environment, 631-632, 887-894. https://doi.org/10.1016/j.scitotenv.2018.03.117

[8] Zhao, S., Fang, J., Miao, S., Gu, B., \& Tang, Z. (2017). The 7-decade degradation of a large freshwater lake in central Yangtze River, China. Environmental Science \& Technology, 39(2), 431-436. https://doi.org/10.1021/es0490875

[9] Chong, J. \& Li. (2016). Effect of ecological restoration and climate change on ecosystems: a case study in the threerivers headwater region, China. Environmental Monitoring and Assessment. 188, Article number: 382. https://doi.org/10.1007/s10661-016-5368-2

[10] Wang, Y., Rhoads, B. L., \& Wang, D. (2016). Assessment of the flow regime alterations in the middle reach of the Yangtze River associated with dam construction: potential ecological implications. Hydrological Processes, 30(21), 3949-3966. https://doi.org/10.1002/hyp.10921

[11] Zhou, R., Zhang, B., \& Wang, S. (2020). Research on Ecological Governance of Smart City in Lhasa under Big Data Environment. IOP Conference Series: Earth and Environmental Science, 580(1), 012072 (6pp). https://doi.org/10.1088/1755-1315/580/1/012072
[12] Zuo, Q., Han, C., Liu, J., Li, J., \& Li, W. (2019). Quantitative research on the water ecological environment of damcontrolled rivers: case study of the Shaying River, China. Hydrological Sciences Journal/Journal des Sciences Hydrologiques, 64(16). https://doi.org/10.1080/02626667.2019.1669794

[13] Xiaofen, J. I., Xinbin, D., Shaoping, L., Daqing, C., \& Dengqiang, W. (2018). Genetic effect of released brood grass carp (ctenopharyngodonidella) on wild population in the Yangtze River inferred from microsatellite markers. Journal of Fisheries of China.

[14] Feng, A., Li, Y., Gao, J., Wu, S., \& Feng, A. (2017). The determinants of streamflow variability and variation in threeriver source of china: climate change or ecological restoration? Environmental Earth Sciences, 76(20), 1-10. https://doi.org/10.1007/s12665-017-7026-6

[15] Jiang, C. \& Zhang, L. (2016). Effect of ecological restoration and climate change on ecosystems: a case study in the threerivers headwater region, China. Environmental Monitoring \& Assessment, 188(6), 382.

https://doi.org/10.1007/s10661-016-5368-2

\section{Contact information:}

\section{Jinhong XIAN}

Institute of Architecture and Engineering,

Chengdu Textile College, China

\section{Yaou ZHANG}

(Corresponding author)

College of Landscape Architecture,

Sichuan Agricultural University,

Sichuan 625014, China

E-mail: 425908090@qq.com 